which may occur in association with sinoatrial block (Short, 1954; Sandoe and Flensted-Jensen, 1969).

The six cases reported here had sinoatrial block with recurrent attacks of dizziness and faintness in all and syncope in three. In three cases sinoatrial block was complicated by paroxysmal supraventricular tachycardia (atrial fibrillation in two, flutter in one). Ventricular pacing was used in all patients, initially with the inductively coupled coil pacemaker, but latterly with a totally implanted demand pacemaker in two. Conversion was made in the latter because of frequent paroxysmal atrial tachyarrhythmias. Relief of symptoms was achieved in all patients, the longest interval with freedom from symptoms being more than five years.

Two criticisms may be made of ventricular pacing for the treatment of sinoatrial block. Firstly, the occurrence of parasystole with the risk of provoking ventricular tachydysrhythmias is a theoretical problem which in practice has proved to be of small significance. The occurrence of sudden death in patients with sinus rhythm with a fixed rate implanted pacemaker was reported by Sowton (1965). Most of these deaths occurred within the early postoperative period and were due to ventricular fibrillation. The risk of such a complication seems to depend on the energy of the stimulating pulse. The energy of the bimodal output of the pulse generator in the inductively coupled coil pacemaker system is probably well below the threshold for provoking ventricular tachydysrhythmias. The haemodynamic effects of parasystole are not disadvantageous (Sowton, 1965).

The second criticism of ventricular pacing for sinoatrial block is that of loss of atrial transport function which is preserved if atrial pacing is used. Sowton (1965) observed that when true synchronization of atrial and ventricular contraction, accrochage, does not occur the cardiac output, as judged by femoral atrial systolic and pulse pressures, is reduced by $25^{\circ}{ }_{0}$. Atrial pacing for sinoatrial block will achieve accrochage, though in the presence of varying sinoatrial block, as seen in some of the cases reported here when block varied from $1: 1$ to complete sinus arrest, competition will occur between sinoatrial node and the electrical pacemaker. Accrochage does occur, if intermittently, in these patients treated with a ventricular pacemaker, and none have shown any sign or symptom of low output failure since pacing was established.

Ventricular pacing does not prevent the occurrence of supraventricular tachydysrhythmias in these patients, but with a variable frequency pulse generator the dysrhythmia may sometimes be suppressed by using a rapid stimulation frequency. It has been possible to suppress tachycardia in this way in two of these cases.

The ideal form of treatment for such patients with sinoatrial block and recurrent episodes of cardiac standstill would be an atrial demand pacemaker. Despite the theoretical objections of parasystole, pacemaker-induced ventricular fibrillation, and loss of accrochage ventricular pacemaking has proved effective in relieving symptoms due to sinoatrial block in the six cases reported here.

I wish to thank Dr. A. Brian Taylor for permission to publish details of patients admitted under his care, and Mr. L. D. Abrams and Mr. D. B. Clarke, who operated on the patients.

\section{References}

Abrams, L. D., Hudson, W. A., and Lightwood, R. (1960). Lancet, 1, 1372. Clarke, M., Evans, D. W., and Milstein, B. B. (1970). British Heart fournal, $32,458$.

Kastor, J. A., De Sanctis, R. W., Leinbach, R. C., Harthorne, J. W., and Wolfson, I. N., (1969). Circulation, 40, 535.

Moss, A. J., Rivers, R. J., and Cooper, M. (1969). Fournal of the American Medical Association, 209, 543.

Sandoe, E., and Flensted-Jensen, E. (1969). Acta Medica Scandinavica, 186,111 .

Shaw, D. B., and Erant, J. (1970). British Heart fournal, 32, 557.

Short, D. S. (1954). British Heart fournal, 16, 208.

Sowton, E. G. (1965). British Heart fournal, 27, 311.

\title{
Prevention of Delayed Traumatic Facial Palsy
}

\author{
M. BRIGGS, J. M. POTTER
}

British Medical fournal, 1971, 3, 458-459

\section{Summary}

A previous impression that corticotrophin provided prophylaxis against delayed traumatic facial palsy has now been confirmed by the results obtained from the first 50 patients so treated.

\section{Introduction}

In a previous communication (Briggs and Potter, 1967) we outlined a scheme of treatment designed to reduce the incidence of delayed traumatic facial palsy and analysed the results of the

\footnotetext{
Department of Neurological Surgery and the Accident Service, Radcliffe Infirmary, Oxford OX2 6HE

M. BRIGGS, F.R.C.S., Postgraduate Research Fellow

J. M. POTTER, D.M., F.R.C.S., Consultant Neurosurgeon
}

first 16 patients so treated. There are now 50 patients who have been given a prophylactic course of corticotrophin gel (cf. Taverner et al., 1966) and the results confirm the protective value of this treatment.

\section{Patients and Methods}

The criteria used for the selection of injured patients who might benefit from prophylactic treatment have been the same as those employed for the earlier 16 patients: all patients who had a bleeding ear and who were shown also to have radiological evidence of a petrous temporal fracture on the same side. We had previously shown, by a retrospective survey of 70 patients with this combination of signs, that $27(38.5 \%)$ developed some degree of delayed facial weakness.

An eight-day course of corticotrophin gel was given, the first dose being administered on the day of injury. The dosage used was as follows: 80 units daily for three days, 60 units on the fourth day, 40 units on the fifth day, 20 units on the sixth day, and 10 units on both the seventh and eighth days. For children this dosage was reduced according to weight: about $1 \cdot 1$ units of corticotrophin being given per $\mathrm{kg} / \mathrm{body}$ weight. 


\section{Results}

Between 15 December 1966 and 12 May 1969 3,544 patients with head injury were admitted to the accident service of the Radcliffe Infirmary. Of these, 50 showed the combination of a fractured petrous temporal bone and bleeding from the ipsilateral ear. Two of these had bilateral fractures and bleeding ears. All received prophylactic corticotrophin soon after injury.

Without treatment we would have expected $19(38 \%)$ of these patients to develop some degree of facial weakness; in fact only $4(8 \%)$ did so, and in our previous paper we mentioned two of these. Of the other two, one developed a severe but incomplete facial weakness on the third day after injury and the other, a 6-year-old boy, developed a very slight weakness five days after injury; both recovered completely.

\section{COMPLICATIONS}

In describing the first 16 of our patients treated with prophylactic corticotrophin we mentioned the complication of severe oedema of the lower abdominal wall and genitalia developing in a $3 \frac{1}{2}$-year-old boy during the eight-day course of treatment. This oedema persisted for five days after the last dose had been given and was thought to have been due to overdosage with corticotrophin. In the next 34 patients we came across this complication once more, in a 5-year-old boy, despite even greater reduction of the dose. On this occasion the oedema resolved completely within six days of the end of his course of treatment.

A second complication was that of acute ocular pain, developing during the third day of the treatment. This occurred on only one occasion and affected a fit young man who had no local injury to account for it. We thought that this was an example of steroid-induced ocular hypertony, similar to steroid-induced glaucoma, which is well documented in the ophthalmological literature-for example, Kent (1969). The pain subsided within a few days of the end of his course of treatment.

Another patient, a 69-year-old man, developed pronounced glycosuria on the third day of treatment. His fasting blood glucose level at this time was $190 \mathrm{mg} / 100 \mathrm{ml}$. A glucose tolerance test carried out after completion of his course of corticotrophin showed a prediabetic type of curve. He was treated with chlorpropamide and a carbohydrate-restricted diet, on which regimen his blood glucose returned to normal and his urine remained free of sugar. In this case it would seem that the corticotrophin unmasked latent diabetes; indeed, steroids have been used for this purpose (Duncan, 1956).

\section{Discussion}

When Taverner et al. (1966) succeeded in reducing the incidence of denervation and increasing the recovery from Bell's palsy by treatment with corticotrophin, we were stimulated to examine the possibility that this form of treatment might also be of value in preventing delayed posttraumatic facial weakness. Indeed, the incidence of this complication in susceptible patients has been reduced from 38.5 to $8 \%$, and there seems to be no doubt therefore that the eight-day course of corticotrophin which we describe does offer considerable protection against delayed traumatic facial palsy.

If the corticotrophin acts solely by raising the circulating plasma cortisol level, one might expect those patients with severe injuries in addition to their petrous fractures to be protected from the complication of delayed facial weakness by a high endogenous cortisol level as part of their metabolic response to "stress" (Thorn et al., 1953). This expectation, however, has not been confirmed by an analysis of our earlier patients with bleeding ears and petrous fractures who did not receive prophylactic corticotrophin. Neither the severity of the head injury, as judged by the length of posttraumatic amnesia, nor that of the associated injuries seems to have altered the expected incidence of this complication. These findings are in keeping with those of Taverner et al. (1966) that, whereas cortisone had no influence on the course of Bell's palsy, corticotrophin significantly reduced the incidence of total denervation.

Despite this demonstration of the effectiveness of corticotrophin in reducing the incidence of delayed posttraumatic facial weakness, we are not convinced that such prophylactic treatment need always be adopted as routine practice; for it is not entirely innocuous. Most patients who do develop this complication of head injury will recover completely, or to an acceptable degree, from their facial weakness without treatment, so the overall value of prophylaxis is relatively slight. Nevertheless, this further evidence of the effect that corticotrophin has on both this and Bell's variety of facial palsy suggests that there is a mechanism, though not an aetiology, common to both conditions.

\section{References}

Briggs, M., and Potter, J. M. (1967). British Medical Fournal, 4, 464.
Duncan, L. J. P. (1956). Quarterly fournal of Experimental Physiology, 41, 453. J. P. (1956). Quarterly Jour

Kent, J. S. (1969). Practitioner, 202, 787. Taverner, D., Fearnley, M. E., Kemble, F.,
(1966). British Medical fournal, 1, 391.

Thorn, G. W., Jenkins, D., and Laidlaw, J. C. (1953). Recent Progress in Hormone Research, 8, 171. 